\title{
Olennaiset vaihtelunlähteet tattaripuurojen aistinvaraisissa kokeissa
}

\author{
Elise Ketoja ${ }^{1)}$, Maarit Mäki $^{2)}$, Pirjo Rantamäki ${ }^{2)}$, Tuomo Tupasela ${ }^{2)}$, Marjo Keskitalo ${ }^{3)}$ ja Anja \\ Lapveteläinen $^{4)}$ \\ ${ }^{1)}$ MTT Palveluyksikkö, 31600 Jokioinen, elise.ketoja@mtt.fi \\ ${ }^{2)}$ MTT Biotekniikka-ja elintarviketutkimus, 31600 Jokioinen, etunimi.sukunimi@mtt.fi \\ ${ }^{3)}$ MTT Kasvintuotannon tutkimus, 31600 Jokioinen, marjo.keskitalo@mtt.fi \\ ${ }^{4)}$ Kuopion yliopisto, Kliinisen ravitsemustieteen yksikkö, ETTK, PL 1627, 70211 Kuopio, \\ anja.lapvetelainen@uku.fi
}

\section{Tiivistelmä}

Tutkimus on osa MTT:ssa vuosina 2003-2007 toteutettua tattarihanketta, jossa yhtenä tavoitteena oli uusien tattarituotteiden kehittely. Tuotekehityksessä lajikkeiden aistinvaraiset ominaisuudet ovat tärkeitä satoisuuden, kemiallisen koostumuksen ja prosessoitavuuden lisäksi. Ominaisuuksien arviointiin kehitettiin vedestä ja tattarista valmistetulle puurolle aistinvarainen profiili määrittelemällä yhdeksän tyypillisintä tattaripuuron makua, hajua, suutuntumaa ja ulkonäköä kuvaavaa ominaisuutta. Profiilia sovellettiin kokeessa, jossa vertailtavana oli neljä MTT:ssa viljeltyä lajiketta. Kahdeksan koulutettua arvioijaa arvioi neljän lajikkeen näytesarjan neljällä eri arviointikerralla. Arvioijat satunnaistettiin näytesarjoihin Williamsin latinalaisia 4x4-neliöitä käyttäen. Ominaisuuksien voimakkuutta mitattiin $10 \mathrm{~cm}: n$ jana-asteikolla lukuun ottamatta värin tummuusastetta, joka mitattiin numeerisella (1-10) asteikolla. Lajikevaikutuksen lisäksi tavoitteena oli saada tietoa muiden arviointipisteisiin vaihtelua aiheuttavien tekijöiden merkityksestä. Mielenkiinto kohdistui erityisesti puurojen arviointijärjestyksen vaikutuksen ja edellisen näytteen jälkivaikutuksen suuruuteen.

Kokeessa ei saatu näyttöä jälkivaikutuksesta. Tähän pyrittiin ohjeistamalla arvioijat neutraloimaan suu vedellä ja tuorekurkulla näytteiden välillä. Tulos voi selittyä osittain myös siitä, että yksikään lajike ei poikennut paljon muista arvioitujen ominaisuuksien voimakkuuksien suhteen. Järjestysvaikutusta sen sijaan esiintyi kaikilla kolmella makuominaisuudella. Näytesarjoissa ensimmäisinä arvioiduilla näytteillä arviointipisteiden estimoidut keskiarvot olivat kaikkein pienimmät. Sen jälkeen keskiarvoissa oli nouseva trendi kolmansina arvioituihin näytteisiin asti. Toisina ja kolmansina arvioitujen näytteiden keskiarvojen ero ei kuitenkaan ollut enää tilastollisesti merkitsevä millään makuominaisuudella. Ero ensimmäisinä ja myöhemmin arvioitujen näytteiden keskiarvojen välillä oli suurimmillaan noin yksi yksikkö kaikilla makuominaisuuksilla. Muista vaikutuksista arvioijavaikutus oli odotetusti suurin vaihtelunlähde. Yhdysvaikutusten (arvioija x arviointikerta, arvioija x lajike, arviointikerta x lajike) osuudet havaintojen vaihtelusta olivat pieniä, mikä kertoo koeolosuhteiden ja arvioijaraadin toiminnan yhdenmukaisuudesta.

Tulokset osoittavat, että erityisesti järjestysvaikutus voi olla aistinvaraisissa kokeissa olennainen vaihtelunlähde, vaikka muut mahdolliset lähteet olisi otettu huomioon. Jälkivaikutustakaan ei voi itsestään selvästi sulkea pois, sillä sen esiintyminen voi riippua tuotteiden ominaisuuksista ja arvioitavien ominaisuuksien määrästä. Tulokset puoltavat sellaisten asetelmien käyttöä aistinvaraisissa kokeissa, jotka ottavat järjestys- ja jälkivaikutuksen esiintymismahdollisuuden huomioon.

Asiasanat: tattari, puuro, aistinvarainen, Williamsin latinalainen neliö, sekamalli, järjestysvaikutus, jälkivaikutus, varianssikomponentti 


\section{Johdanto}

Elintarviketuotteiden kehittelyssä pyritään vertailemaan tuotteiden aistinvaraisia ominaisuuksia suunnitelluilla kokeilla, joissa koulutettu raati arvioi tuotteet kontrolloiduissa olosuhteissa. Kokeet tulisi suunnitella ja toteuttaa niin, että tuotteiden välisten erojen estimaatit ovat harhattomia ja koevirhe mahdollisimman pieni. Tämä edellyttää sitä, että tuotteiden lisäksi muut olennaiset arviointipisteisiin vaihtelua aiheuttavat tekijät otetaan kokeissa huomioon ja niiden vaikutukset eliminoidaan tuotevertailuista.

MTT:ssa vuosina 2003-2007 toteutetussa Terveyttä tattarista -hankkeessa oli yhtenä tavoitteena tattarin uusien käyttömahdollisuuksien esille tuominen ja soveltaminen elintarvikkeisiin. Uusien tattarituotteiden kehittelyssä lajikkeiden aistinvaraiset ominaisuudet ovat tärkeitä satoisuuden, kemiallisen koostumuksen ja prosessoitavuuden lisäksi. Lajikkeiden aistinvaraisten ominaisuuksien arviointiin kehitettiin vedestä ja tattarista valmistetulle puurolle profiili määrittelemällä yhdeksän tyypillisintä tattaripuuron makua, hajua, suutuntumaa ja ulkonäköä kuvaavaa ominaisuutta. Profiilia sovellettiin kokeessa, jossa vertailtavana oli neljä MTT:ssa viljeltyä lajiketta. Kokeen tavoitteena oli lajikevaikutuksen lisäksi saada tietoa muiden arviointipisteisiin vaihtelua aiheuttavien tekijöiden merkityksestä. Mielenkiinto kohdistui erityisesti lajikkeiden arviointijärjestyksen vaikutuksen ja edellisen näytteen jälkivaikutuksen suuruuteen. Järjestys- ja jälkivaikutuksen on osoitettu riippuvan tuotteesta ja arvioitavista ominaisuuksista (Huon de Kermadec \& Pagès 2005, Durier ym. 1997, Schlich 1993, Muir \& Hunter 1991). Vaikutusten esiintymisestä puurojen aistinvaraisissa kokeissa ei ole tiedossa aiempia tutkimuksia. Tulokset auttavat suunnittelemaan tehokkaita ja luotettavia kokeita tattarilajikkeiden astinvaraisten ominaisuuksien vertailuun. Käytettyä lähestymistapaa voidaan soveltaa periaatteessa minkä tahansa tuotteen aistinvaraisissa kokeissa.

\section{Aineisto ja menetelmät}

Tutkimusaineisto perustui MTT:n aistinvaraisessa laboratoriossa Jokioisissa vuonna 2006 tehtyyn kokeeseen, jossa verrattiin neljää MTT:ssa viljeltyä tattarilajiketta. Kahden lajikkeen ('Ilkka', 'Keskinen') alkuperämaa oli Suomi ja kahden ('Kora', 'Panda') Puola. Lajikkeiden vertailuun käytettiin vedestä ja tattarista valmistetulle puurolle kehitettyä profiilia (Lapveteläinen ym. 2005), jossa tyypillisimmiksi puuron aistinvaraisiksi ominaisuuksiksi määriteltiin kaksi hajua (perunamainen ja viljainen/rukiinen), kolme makua (karvaus, tattarin ominaismaku ja yleisvoimakkuus), kaksi rakenneominaisuutta (ryynimäisyys ja leseisyys) ja kaksi ulkonäköominaisuutta (kirjavuus ja värin tummuus). Ominaisuuksien voimakkuutta mitattiin päistään ankkuroidulla $10 \mathrm{~cm}: n$ jana-asteikolla. Poikkeuksena oli värin tummuusaste, joka mitattiin numeerisella (1-10) asteikolla. Kohdat 2 ja 9 oli ankkuroitu voimakkuustasoilla, joita edustivat mallivärit (2=NCS värimalli S3010-Y90R ja 9=S2005Y90R).

Kokeessa oli kahdeksan koulutettua arvioijaa, joista jokainen arvioi neljän lajikkeen näytesarjan. Näytteiden välillä arvioijat huuhtelivat suuta vedellä ja söivät tuoreen kurkunpalan. Arviointikertoja oli neljä 10 päivän aikana ja eri kerroilla puurot valmistettiin kenttäkokeen eri lohkoista saaduista suurimoista. Arvioijat satunnaistettiin näytesarjoihin Williamsin latinalaisia 4x4neliöitä käyttäen (Williams 1949). Koska arvioijia oli kahdeksan, samaa neliötä toistettiin kahdesti arviointikertojen sisällä, mutta neliö vaihdettiin kertojen välillä valitsemalla tarvittavat neliöt satunnaisesti kuuden mahdollisen neliön joukosta. Kussakin Williamsin neliössä jokaisen lajikkeen puuro tulee näytesarjassa arvioiduksi ensimmäisenä, toisena, kolmantena ja neljäntenä tarkalleen kerran. Lisäksi jokaisen lajikkeen näyte arvioidaan kerran jokaisen kolmen muun lajikkeen näytteen jälkeen (Taulukko 1). Koeasetelman perusteella on mahdollista estimoida ja testata sekä arviointijärjestys- että jälkivaikutus ja eliminoida ne lajikevertailusta. 
Taulukko 1. Esimerkki yhdestä kokeessa käytetystä Williamsin latinalaisesta 4x4-neliöstä. Neljä lajiketta satunnaistettiin kirjaimiin A, B, C, ja D ja sen jälkeen arvioijat satunnaistettiin näytesarjoihin.

\begin{tabular}{|l|llll|}
\hline & \multicolumn{4}{|c|}{ Arviointijärjestys } \\
\hline Arvioija 1 & 1. & 2. & 3. & 4. \\
Arvioija 2 & A & C & D & B \\
Arvioija 3 & D & A & B & C \\
Arvioija 4 & C & B & A & D \\
\hline
\end{tabular}

Arvioitujen ominaisuuksien tilastolliset analyysit perustuivat seuraavaan lineaariseen sekamalliin:

$$
\mathrm{y}_{\mathrm{ijk}}=\mu+\mathrm{A}_{\mathrm{i}}+\mathrm{O}_{\mathrm{i}}+\mathrm{L}_{\mathrm{d}(\mathrm{i}, \mathrm{i}, \mathrm{k})}+\mathrm{L}_{\mathrm{d}(\mathrm{i}, \mathrm{i}-1, \mathrm{k}, \mathrm{k})}+\mathrm{S}_{\mathrm{k}}+(\mathrm{AL})_{\mathrm{id}}+(\mathrm{AS})_{\mathrm{ik}}+(\mathrm{LS})_{\mathrm{dk}}+\varepsilon_{\mathrm{ijk}}
$$

missä $y_{i j k}$ on arvioijan $i$ arviointikerralla $k$ antama ominaisuuden voimakkuutta kuvaava numeerinen arvio j:ntenä arvioidulle lajikkeelle $\mathrm{d}(\mathrm{i}, \mathrm{j}, \mathrm{k}) \quad(\mathrm{i}=1, \ldots, 8, \mathrm{j}=1, \ldots, 4, \mathrm{~d}=1, \ldots, 4, \mathrm{k}=1, \ldots, 4) ; \mu$ on yleiskeskiarvo, $A_{i}$ on arvioijan i satunnaisvaikutus, $O_{i}$ on arviointijärjestyksen $\mathrm{j}$ kiinteä vaikutus, $\mathrm{L}_{\mathrm{d}(\mathrm{i}, \mathrm{j}, \mathrm{k})}$ on lajikkeen $d(\mathrm{i}, \mathrm{j}, \mathrm{k})$ kiinteä (suora) vaikutus, $\mathrm{L}_{\mathrm{d}(\mathrm{i}, \mathrm{j}-1, \mathrm{k})}$ on lajikkeen $\mathrm{d}(\mathrm{i}, \mathrm{j}-1, \mathrm{k})$ kiinteä jälkivaikutus $(\mathrm{j} \geq 2$, $\mathrm{L}_{\mathrm{d}(\mathrm{i}, 0, \mathrm{k})}$ oletetaan nollaksi), $\mathrm{S}_{\mathrm{k}}$ on arviointikerran $\mathrm{k}$ satunnaisvaikutus, $(\mathrm{AL})_{\mathrm{id}} \mathrm{ja}(\mathrm{AS})_{\mathrm{ik}}$ ovat arvioijan $\mathrm{i}$ yhdysvaikutuksia lajikkeen $\mathrm{d}(\mathrm{i}, \mathrm{j}, \mathrm{k})$ ja arviointikerran $\mathrm{k}$ kanssa, (LS) $)_{\mathrm{dk}}$ on lajikkeen $\mathrm{d}(\mathrm{i}, \mathrm{j}, \mathrm{k}) \mathrm{ja}$ arviointikerran $\mathrm{k}$ yhdysvaikutus ja $\varepsilon_{\mathrm{ijk}}$ on virhetermi. Satunnaismuuttujista $\mathrm{A}_{\mathrm{i}}$ oletetaan, että ne ovat riippumattomia ja noudattavat normaalijakaumaa, jonka keskiarvo on nolla ja varianssi $\sigma_{\mathrm{A}}{ }^{2}$, ts. $\mathrm{A}_{\mathrm{i}} \sim$ iid $\mathrm{N}\left(0, \sigma_{\mathrm{A}}^{2}\right)$, Vastaavat oletukset tehdään myös muista satunnaismuuttujista: $\mathrm{S}_{\mathrm{k}} \sim$ iid $\mathrm{N}\left(0, \sigma_{\mathrm{S}}{ }^{2}\right),(\mathrm{AL})_{\mathrm{id}} \sim$ iid $\mathrm{N}\left(0, \sigma_{\mathrm{AL}}^{2}\right),(\mathrm{AS})_{\mathrm{ik}} \sim$ iid $\mathrm{N}\left(0, \sigma_{\mathrm{AS}}{ }^{2}\right),(\mathrm{LS})_{\mathrm{dk}} \sim$ iid $\mathrm{N}\left(0, \sigma_{\mathrm{LS}}^{2}\right)$ ja $\varepsilon_{\mathrm{ijk}} \sim$ iid $\mathrm{N}\left(0, \sigma^{2}\right)$. Lisäksi satunnaismuuttujat $\mathrm{A}_{\mathrm{i}}, \mathrm{S}_{\mathrm{k}},(\mathrm{AL})_{\mathrm{id}},(\mathrm{AS})_{\mathrm{ik}},(\mathrm{LS})_{\mathrm{dk}}$ ja $\varepsilon_{\mathrm{ijk}}$ oletetaan toisistaan riippumattomiksi.

Estimointimenetelmänä mallien sovituksessa oli REML (restricted maximum likelihood method) -menetelmä. Lajike-, järjestys- ja jälkivaikutuksen merkitsevyydet testattiin F-testeillä, joiden vapausasteet määrättiin Kenwardin ja Rogerin (1997) menetelmällä. Keskiarvojen väliset erot testattiin kaksisuuntaisilla t-tyyppisillä testeillä. Mallien aineistoa koskevien oletusten paikkansapitävyyttä tarkasteltiin graafisesti. Jäännösten jakauman normaalisuus tarkistettiin Tukeyn laatikko-jana-kuvion avulla (Tukey 1977) ja vakiovarianssisuus piirtämällä jäännökset koordinaatistoon sovitearvoja vastaan. Kuvien perusteella mallioletukset olivat jokaisella ominaisuudella likimain voimassa. Analyysit toteutettiin SAS/STAT-ohjelmiston MIXEDproseduurilla (Littell et al. 2006).

\section{Tulokset ja tulosten tarkastelu}

Kokeessa ei saatu näyttöä edellisen näytteen jälkivaikutuksesta millään arvioidulla ominaisuudella (Taulukko 2). Jälkivaikutuksen minimointiin pyrittiin ohjeistamalla arvioijat neutraloimaan suu vedellä ja tuorekurkulla näytteiden välillä. Tulos voi selittyä osittain myös siitä, että yksikään lajike ei poikennut paljon muista arvioitujen ominaisuuksien voimakkuuksien suhteen. Lajikkeiden välillä oli tilastollisesti merkitseviä eroja ainoastaan puuron ulkonäköominaisuuksissa (Taulukko 2). Jälkivaikutuksen on havaittu riippuvan myös arvioitavien ominaisuuksien määrästä. Ferrisin ym. (2003) tutkimuksessa, jossa vertailtiin kahdeksaa juustotyyppiä 11 kokeessa, jälkivaikutuksesta saatiin voimakkaampaa todistetta niissä kokeissa, joissa arvioitavia ominaisuuksia oli yksi tai neljä verrattuna kokeeseen, jossa ominaisuuksia oli 25. Lyhyt aikaväli saman ominaisuuden arvioinnissa peräkkäisistä näytteistä voi lisätä jälkivaikutuksen esiintymismahdollisuutta.

Järjestysvaikutusta puolestaan esiintyi kaikilla kolmella makuominaisuudella, mutta karvaudella vaikutus ei ollut tilastollisesti merkitsevä (Taulukko 2). Näytesarjoissa ensimmäisinä arvioiduilla näytteillä arviointipisteiden estimoidut keskiarvot olivat kaikkein pienimmät. Sen jälkeen keskiarvoissa oli nouseva trendi kolmansina arvioituihin näytteisiin asti (Kuva 1). Toisina ja kolmansina arvioitujen näytteiden keskiarvojen ero ei kuitenkaan ollut enää tilastollisesti merkitsevä millään makuominaisuudella $(\mathrm{p}>0.25)$. Ero ensimmäisinä ja myöhemmin arvioitujen näytteiden keskiarvojen välillä oli suurimmillaan noin yksi yksikkö kaikilla makuominaisuuksilla. Muir ja Hunter (1991) havaitsivat 12 Cheddar-juustomerkin aistinvaraisessa kokeessa vastaavanlaisen yhteyden arviointijärjestyksen ja negatiivisten ominaisuuksien $(\mathrm{mm}$. eltaantunut maku) välillä. Positiivisilla 
ominaisuuksilla yhteys oli päinvastainen: voimakkuusarviot laskivat arviointijärjestyksen kasvaessa. Todistetta siitä, että ensimmäisinä arvioidut näytteet voivat olla eri asemassa kuin muut näytteet, ovat raportoineet myös Huon de Kermadec ja Pagès (2005).

Taulukko 2. Järjestys-, jälki- ja lajikevaikutustestien tulokset tattaripuuron yhdeksän ominaisuuden tilastollisissa analyyseissa. DF = Kenwardin ja Rogerin menetelmällä määrätyt nimittäjän vapausasteet F-testissä. Osoittajan vapausasteet $=3$ kaikissa testeissä.

\begin{tabular}{|ll|rcc|ccc|ccc|}
\hline & & \multicolumn{3}{|c|}{ Järjestysvaikutus } & \multicolumn{3}{c|}{ Jälkivaikutus } & \multicolumn{3}{c|}{ Lajikevaikutus } \\
& Ominaisuus & DF & F-arvo & P-arvo & DF & F-arvo & P-arvo & DF & F-arvo & P-arvo \\
\hline \multirow{2}{*}{ Maku: } & Tattarin maku & 77 & 2,83 & $\mathbf{0 , 0 4}$ & 82 & 2,05 & 0,11 & 10 & 0,87 & 0,49 \\
& Karvaus/kitkeryys & 79 & 1,87 & $\mathbf{0 , 1 4}$ & 85 & 1,15 & 0,33 & 11 & 0,54 & 0,67 \\
& Kokonaisvoimakkuus & 77 & 3,33 & $\mathbf{0 , 0 2}$ & 82 & 0,39 & 0,76 & 10 & 0,47 & 0,71 \\
Haju: & Perunamainen & 88 & 1,21 & 0,31 & 95 & 1,38 & 0,25 & 87 & 0,72 & 0,54 \\
& Rukiinen & 87 & 2,12 & 0,10 & 91 & 0,51 & 0,68 & 87 & 0,50 & 0,68 \\
Suutuntuma: & Ryynimäisyys & 79 & 0,88 & 0,45 & 87 & 0,38 & 0,76 & 13 & 0,35 & 0,79 \\
& Leseisyys & 76 & 0,70 & 0,55 & 80 & 0,11 & 0,96 & 11 & 0,62 & 0,62 \\
\multirow{4}{*}{ Ulkonäkö: } & Kirjavuus & 77 & 1,83 & 0,15 & 82 & 2,22 & 0,09 & 9 & 6,70 & $\mathbf{0 , 0 1}$ \\
& Värin tummuus & 76 & 2,51 & 0,07 & 80 & 1,38 & 0,26 & 13 & 10,72 & $\mathbf{0 , 0 0 1}$ \\
\hline
\end{tabular}

(a) Tattarin maku

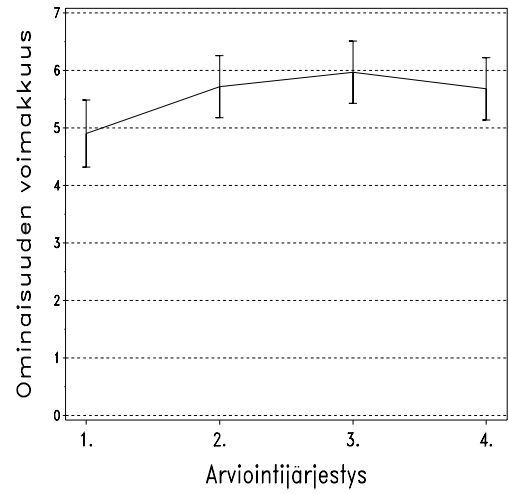

(b) Maun karvaus / kitkeryys

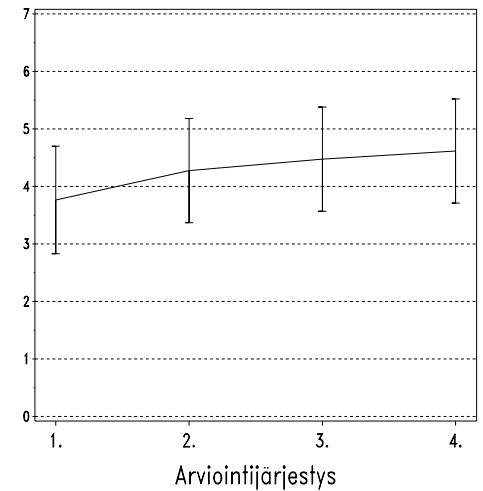

(c) Kokonaisvoimakkuus

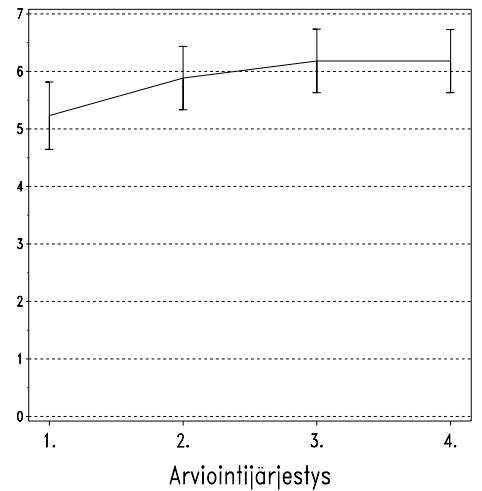

Kuva 1. Arviointijärjestyksen vaikutus tattaripuuron kolmen makuominaisuuden keskimääräisiin voimakkuuksiin (keskiarvoestimaatit \pm keskiarvojen keskivirheet). Vierekkäisiä arviointijärjestyksiä verrattaessa vain 1. ja 2. välinen ero oli tilastollisesti merkitsevä tattarin ominaismaulla ja maun kokonaisvoimakkuudella $(\mathrm{p}<0.05)$.

Edellä esitettyä tilastollista mallia käytettäessä havaintojen varianssi voidaan jakaa kuuteen komponenttiin: $\operatorname{var}\left(\mathrm{y}_{\mathrm{ijk}}\right)=\sigma_{\mathrm{S}}^{2}+\sigma_{\mathrm{A}}^{2}+\sigma_{\mathrm{AS}}^{2}+\sigma_{\mathrm{LS}}^{2}+\sigma_{\mathrm{AL}}^{2}+\sigma^{2}$. Kaksi ensimmäistä komponenttia $\sigma_{\mathrm{S}}^{2} \mathrm{ja}$ $\sigma_{\mathrm{A}}^{2}$ ovat arviointikertojen ja arvioijien välisen vaihtelun määrää kuvaavat varianssit ja viimeinen $\sigma^{2}$ on jäännösvarianssi. Yhdysvaikutuksiin liittyvät varianssit $\sigma_{\mathrm{AS}}{ }^{2}$ (arvioija $\mathrm{x}$ arviointikerta), $\sigma_{\mathrm{LS}}{ }^{2}$ (lajike $\mathrm{x}$ arviointikerta) ja $\sigma_{\mathrm{AL}}^{2}$ (arvioija $\mathrm{x}$ lajike) ovat nollaa suurempia silloin, kun yhdysvaikutuksia esiintyy aineistossa. Estimoimalla varianssikomponentit ja laskemalla kunkin komponentin prosenttinen osuus kaikkien varianssikomponenttien summasta nähdään, kuinka suuri osa havainnoissa esiintyvästä vaihtelusta selittyy eri satunnaisvaikutuksista (Taulukko 3). Osuuksia tarkastelemalla saadaan tietoa koeolosuhteiden ja raadin toiminnan yhdenmukaisuudesta sekä arvioijien kyvystä toistaa kullekin lajikkeelle antamansa arviot eri arviointikerroilla.

Satunnaisvaikutuksista arvioijavaikutus oli odotetusti suurin vaihtelunlähde kaikilla ominaisuuksilla. Arvioijavaikutusta aiheuttavat yksilölliset erot mm. aistien herkkyyksissä ja mittaasteikon käytössä. Arvioijat eivät myöskään välttämättä ymmärrä tuotteen ominaisuuksia aina samalla tavalla. Koulutuksella arvioijien välisiä eroja voidaan pienentää, mutta täysin niistä ei koskaan päästä eroon. 
Arvioijan ja lajikkeen yhdysvaikutusten osuudet olivat nollia tai pieniä kaikilla ominaisuuksilla, mikä tarkoittaa sitä, että arviot lajikkeiden välisistä eroista eivät olennaisesti vaihdelleet arvioijalta toiselle. Näin tulee olla hyvin koulutettua raatia käytettäessä. Tässä kokeessa tulosta selittää lisäksi lajikkeiden välisten erojen vähäisyys. Toivottavaa on myös, että lajikkeiden väliset erot eivät vaihtele paljon arviointikerralta toiselle, ts. aineistossa ei esiinny arviointikerran ja lajikkeen yhdysvaikutusta. Selvimmät lajikkeiden väliset erot havaittiin puuron värin tummuusasteessa: tummimmaksi arvioitiin 'Ilkka' (keskiarvo 7.2) ja vaaleimmaksi 'Kora' (keskiarvo 4.3). Koska erot lajikkeiden välillä olivat suurempia kuin muilla ominaisuuksilla, niissä esiintyi myös suurempaa vaihtelua eri arviointikerroilla. Tämän vuoksi arviointikerran ja lajikkeen yhdysvaikutuksen osuus havaintojen varianssista oli värin tummuudella kaikkein suurin.

Selittämättömän vaihtelun määrää kuvaavien jäännösvarianssien osuudet olivat suurimmat kahdella puuron tuoksua kuvaavalla ominaisuudella, jotka monet raadin jäsenet kokivat muita ominaisuuksia haasteellisemmiksi arvioida. Hajujen arviointi on vaikeampaa kuin esimerkiksi värin arviointi, koska siihen ei ole olemassa kaikkien ymmärtämää ja hyväksymää, tieteelliseen käyttöön sopivaa yleissanastoa, vaan arvioijat koulutetaan ko. ominaisuuksien arviointiin erillisten vertailunäytteiden avulla (Tuorila ym. 2005). Hajujen aistiminen riippuu olennaisesti myös monista muista seikoista, kuten esimerkiksi näytteiden lämpötilasta, näyteastian sulkemisnopeudesta haistamisen jälkeen, arviointitilan ilmastoinnin tehokkuudesta sekä itse hajuaistin adaptoitumisesta. Hajujen arviointiin liittyvät vaikeudet saattavat selittää myös arviointikerran ja arvioijan yhdysvaikutuksen osuuden suuruutta rukiisella hajulla. Arviointikertojen välinen vaihtelu oli vähäistä kaikilla ominaisuuksilla.

Taulukko 3. Satunnaisvaikutusten osuudet (\%) havaintojen varianssista tattaripuuron eri ominaisuuksien tilastollisissa analyyseissa. Luvut on saatu jakamalla kuhunkin satunnaisvaikutukseen liittyvä varianssikomponentti kaikkien varianssikomponenttien summalla ja kertomalla osamäärä 100:1la.

\begin{tabular}{|ll|c|c|c|c|c|c|}
\hline & Ominaisuus & Arvioija & $\begin{array}{c}\text { Arvioija } \\
\text { x lajike }\end{array}$ & $\begin{array}{c}\text { Arviointi- } \\
\text { kerta }\end{array}$ & $\begin{array}{c}\text { Arv.kerta } \\
\text { x arvioija }\end{array}$ & $\begin{array}{c}\text { Arv.kerta } \\
\text { x lajike }\end{array}$ & Jäännös \\
\hline \multirow{2}{*}{ Maku: } & Tattarin maku & 54 & 3 & 0 & 9 & 1 & 33 \\
& Karvaus/kitkeryys & 77 & 0 & 2 & 2 & 0 & 19 \\
& Kokonaisvoimakkuus & 58 & 1 & 0 & 10 & 2 & 28 \\
Haju: & Perunamainen & 51 & 0 & 2 & 4 & 0 & 43 \\
& Rukiinen & 43 & 0 & 0 & 18 & 0 & 39 \\
Suutuntuma: & Ryynimäisyys & 62 & 0 & 0 & 1 & 2 & 35 \\
& Leseisyys & 77 & 2 & 0 & 4 & 1 & 16 \\
\multirow{4}{*}{ Ulkonäkö: } & Kirjavuus & 82 & 0 & 0 & 4 & 1 & 13 \\
& Värin tummuus & 38 & 8 & 2 & 7 & 14 & 31 \\
\hline
\end{tabular}

\section{Johtopäätökset}

Elintarvikkeiden aistinvaraisia kokeita toteutetaan usein siten, että tuotteiden arviointijärjestys arvotaan jokaisen arvioijan kohdalla erikseen käyttämällä täydellistä satunnaistamista (Lea ym. 1997). Tällainen menettely ei takaa sitä, että kaikki tuotteet tulevat arvioiduiksi yhtä monta kertaa kaikissa mahdollisissa järjestyksissä. Tuloksemme yhdessä aikaisempien tulosten kanssa osoittavat, että järjestysvaikutus voi olla olennainen vaihtelunlähde elintarvikkeiden aistinvaraisissa kokeissa, vaikka muut mahdolliset lähteet olisi otettu huomioon. Erityisesti ensimmäisinä arvioidut näytteet voivat olla eri asemassa kuin muut näytteet. Tässä tutkimuksessa ero ensimmäisinä ja myöhemmin arvioitujen näytteiden arviointipisteiden keskiarvojen välillä oli suurimmillaan noin yksi yksikkö kaikilla makuominaisuuksilla. Näin suuret järjestysvaikutukset voivat vääristää tuotteiden vertailua, ellei niitä oteta kokeissa huomioon.

Jälkivaikutustakaan ei voi itsestään selvästi sulkea pois, sillä sen esiintyminen voi riippua mm. tuotteiden ominaisuuksista ja arvioitavien ominaisuuksien määrästä. Käytetyssä tilastollisessa mallissa oletetaan, että jälkivaikutus riippuu vain juuri edellä arvioidusta tuotteesta. Kullakin tuotteella 
oletetaan siis olevan "oma" jälkivaikutus, joka ei riipu seuraavasta (arvioitavana olevasta) eikä edeltävästä tuotteesta. Tällainen oletus voi olla käytännössä liian yksinkertainen. Sen vuoksi on suositeltavaa yrittää minimoida jälkivaikutukset neutraloimalla suu näytteiden välillä. Vaihtoehtoisia jälkivaikutusmalleja on myös kehitelty (Jones \& Kenward 2003).

Arvioijavaikutus oli tässä tutkimuksessa olennainen vaihtelunlähde, kuten yleensäkin aistinvaraisissa kokeissa, mikä tulee ottaa huomioon kokeiden suunnittelussa ja analysoinnissa. Yhdysvaikutusten (arvioija $\mathrm{x}$ arviointikerta, arvioija $\mathrm{x}$ lajike, arviointikerta $\mathrm{x}$ lajike) osuudet havaintojen vaihtelusta olivat pieniä kaikilla ominaisuuksilla, mikä kertoo koeolosuhteiden ja raadin toiminnan yhdenmukaisuudesta.

Tulokset puoltavat sellaisten asetelmien käyttöä aistinvaraisissa kokeissa, jotka ottavat järjestysja jälkivaikutuksen esiintymismahdollisuuden huomioon. Tässä tutkimuksessa käytetyssä Williamsin koeasetelmassa jokainen tuote arvioidaan kerran jokaisen muun tuotteen jälkeen. Tämä on mahdollista vain, jos tuotteita on parillinen määrä. Parittomilla tuotemäärillä voidaan käyttää kahta neliötä, jolloin jokainen tuote tulee arvioiduksi kaksi kertaa jokaisen muun tuotteen jälkeen. Myös muita vaihtoehtoja löytyy parittomille tuotemäärille (Jones \& Kenward 2003). Williamsin asetelmassa lisäksi jokainen arvioija arvioi kaikki tuotteet. Jos se ei ole mahdollista suuren näytemäärän vuoksi, käytettävissä on runsaasti vaihtoehtoisia koeasetelmia (Jones \& Kenward 2003, Ball 1997).

\section{Kiitokset}

Kiitämme arvokkaasta avusta kaikkia arvioijaraadin jäseniä sekä Seija Tuomarmäkeä ja Paula Laaksosta.

\section{Kirjallisuus}

Ball, R.D. 1997. Incomplete block designs for the minimisation of order and carry-over effects in sensory analysis. Food Quality and Preference 8: 111-118.

Durier, C., Monod, H. \& Bruetschy, A. 1997. Deisgn and analysis of factorial sensory experiments with carryover effects. Food Quality and Preference 8: 141-149.

Ferris, S.J., Kempton, R.A. \& Muir, D.D. 2003. Carryover in sensory trials. Food Quality and Preference 14: 299-304.

Huon de Kermadec, F. \& Pagès, J. 2005. Methodology to analyse rank and carry-over effects. Food Quality and Preference 16: 600-607.

Jones, B. \& Kenward, M.G. 2003. Design and Analysis of Cross-Over Trials, Second Edition, Chapman \& Hall/CRC, Boca Raton. 382 ss.

Kenward, M.G. \& Roger, J.H. 1997. Small sample inference for fixed effects from restricted maximum likelihood. Biometrics 53: 983-997.

Lapveteläinen, A., Rantamäki, P., Ketoja, E., Tupasela, T. \& Mäki, M. 2005. Sensory profiling of buckwheat porridge. In: The 6th Pangborn Sensory Science Symposium, 7 - 11 August 2005, Harrogate International Centre, North Yorkshire, UK, Symposium Programme \& Abstract Book. 1 p. (Abstract).

Lea, P., Næs, T. \& Rødbotten, M. 1997. Analysis of Variance for Sensory Data. John Wiley \& Sons, Chichester. 102 ss.

Littell, R.C., Milliken, G.A., Stroup, W.W., Wolfinger, R.D. \& Schabenberger, O. 2006. SAS $^{\circledR}$ for Mixed Models, Second Edition. Cary, NC: SAS Insitute Inc. 814 ss.

Muir, D.D. \& Hunter, E.A. 1991. Sensory evaluation of cheddar cheese: order of tasting and carryover effects. Food Quality and Preference 3: 141-145.

Schlich, P. 1993. Uses of change-over designs and repeated measurements in sensory and consumer studies. Food Quality and Preference 4: 223-235.

Tukey, J.W. 1977. Exploratory Data Analysis. Addison-Wesley, Reading, MA. 688 ss.

Tuorila, H. \& Appelbye, U. (toim.). 2005. Elintarvikkeiden aistinvaraiset tutkimusmenetelmät. Yliopistopaino, Helsinki. 286 ss.

Williams, E.J. 1949. Experimental designs balanced for the estimation of residual effects of treatments. Australian Journal of Scientific Research 2: 149-168. 